\title{
Research on the Industrial Development System Construction of Contemporary Inheritance of Chinese Traditional Painting Art
}

\author{
Hui Lin ${ }^{1,3}$, Yan Cheng ${ }^{2,3}$, Xiaogang Chen ${ }^{1,3}$ \\ ${ }^{1}$ College of Urban Construction, Jiangxi Normal University, Nanchang 330022, China \\ ${ }^{2}$ College of Fine Arts, Jiangxi Normal University, Nanchang, 330022, China \\ ${ }^{3}$ Geodesign Research Centre, Jiangxi Normal University, Nanchang 330022, China
}

\begin{abstract}
Based on the necessity of constructing the development system of the contemporary inheritance industry of Chinese traditional painting art, this paper proposes five system construction elements: inheritance subject, inheritance mode, inheritance content, inheritance field and inheritance guarantee by analyzing the integrated development mode of the development of art industry and the inheritance of painting art. Combined with the unique points of the inheritance and development of Traditional Chinese painting art and the inherent laws of the development of the art industry, the paper analyzes and constructs an industrial development system dominated by the core art industry chain and supplemented by the external inheritance guarantee system. It aims to make the development of the art industry cooperate with the contemporary inheritance of Chinese traditional painting art, and jointly promote the contemporary inheritance of Chinese traditional painting art.
\end{abstract}

Keywords: Traditional painting, Contemporary inheritance, Art industry, System building.

\section{Introduction}

Chinese traditional painting art is the artistic treasure of Chinese traditional culture. Under the background of innovative economy in the 21 st century, it is facing the confusion and hindrance of creative transformation and innovative development. At the same time, China's art industry is thriving. As a sunrise industry, it needs to shoulder the mission of inheriting and carrying forward the excellent culture of the Chinese nation. It is not only the inevitable trend to realize the contemporary inheritance of Chinese traditional painting art, but also the key way to promote the excellent traditional painting art of the Chinese nation. However, due to the late start of theoretical research and practice development of China's painting art industry, and the unique inheritance of Traditional Chinese painting art, a relatively systematic, comprehensive and perfect industrial system of traditional Chinese painting art inheritance has not been formed. Therefore, it is necessary to carry out an in-depth analysis of the connotation and organizational form of the construction elements of its inheritance industry development system, so as to effectively build an industrial development system for the contemporary inheritance of Chinese traditional painting art.

\section{The Necessity of Constructing the Contemporary Inheritance Industry Development System of Chinese Traditional Painting Art}

2.1 The Inherent Demand for the Inheritance and Protection of Traditional Chinese Painting Art and the Inevitable Trend of Innovation and Development

Chinese traditional painting art has a long history. After thousands of years of continuous inheritance and development, it has formed a unique national style and a wide range of painting art system. To the 20th century, the Chinese traditional painting art, under the interweaving of foreign culture and modern consciousness, gradually began to innovate, and its name, technique, form, function and utility, value symbol and other aspects have undergone great changes. With the comprehensive introduction of western art forms, modern and contemporary painting has developed a series of traditional painting art techniques, forms and ideas combining Chinese and western elements, highlighting the unique characteristics and innovation of The Times, and making a breakthrough contribution to enrich the era of traditional Chinese painting art. But with the continuous development of economic globalization, the contemporary traditional Chinese painting art heritage and development problems begin to growing, all kinds of Chinese traditional painting art suffered varying degrees of marginalized crisis, which has a distinct national characteristics of Chinese painting as the mainstream of Chinese traditional painting pictures, though its artistically but increasingly, they still have a place, The other traditional Chinese paintings whose original functions have declined or even been replaced are in a precarious situation. Nowadays, western art education concept has quietly infiltrated into China's art education system, resulting in the creation results of many mainstream traditional painting art types in contemporary China increasingly show the trend of genetic alienation, and Chinese traditional painting art is more and more difficult to fit the Aesthetic psychology and value orientation of Chinese people. However, many traditional painting art has been neglected, misunderstood or even distorted, and finally has to face the end of wither, decline and even extinction.

Chinese traditional painting art has artistic characteristics and cultural characteristics completely different from western traditional painting art, unique national character should be an important foundation for its inheritance and protection, and Chinese traditional painting art must adapt to the aesthetic needs of people in the new era, so synchronized development with the trend of The Times is the requirement of innovation and development. Nowadays, whether it is the inherent need of the reform of traditional Chinese painting art itself or the 
inevitable trend of innovation and development, it indicates the need to combine traditional Chinese painting art with the development of art industry. Based on the protection and renewal, carry forward the distinct national characteristics and deep connotation of the national heritage development idea to construct the contemporary traditional Chinese painting art heritage industry system, on the one hand can effectively clear and eliminate negative factors of Chinese traditional painting inside the original and the feudal dross, make the positive factors in the traditional Chinese painting art and the culture essence to carry forward; On the other hand, it can timely remove the homogenization crisis of Chinese traditional painting art caused by excessive introduction and reference of foreign western art, which is conducive to the formation of a new look of Chinese traditional painting art in the new period, which not only embodies the vitality of The Times but also contains profound and excellent traditional culture. Therefore, the construction of the contemporary inheritance industry system of Chinese traditional painting art should be the best breakthrough strategy for the inheritance, protection and innovation development of Chinese traditional painting art.

\subsection{Strong Support to Enhance the Competitiveness of Chinese Art Industry in the International Market}

The commercialization and marketization of Chinese traditional painting art has a long history. In the Han Dynasty, relatively pure art painting and calligraphy market has taken shape, known as "commission book" "commission painting" market. By the Tang Dynasty, the market of painting and calligraphy had formed. Through the alteration of Zhang Huaiguan's guan and Zhang Yanyuan's Guan, we can see the situation of collection and transaction of painting and calligraphy at that time. The song Dynasty's painting and calligraphy art flourished, and the Song Dynasty's painting and calligraphy market was also increasingly prosperous. At that time, painting and calligraphy shops were all over the city's streets and alleys, professional painters and calligraphers, intermediaries, fixed painting and calligraphy trading places and fake markets began to emerge widely, and art consumer groups continued to expand. In the Yuan Dynasty, the painting and calligraphy market continued to develop. At this time, painters, brokers and collectors had a strong sense of market economy. Until the Ming Dynasty, the painting and calligraphy market became richer and more diverse, and artistic economic activities became more active. It was generally handled by painting dealers and operated by the market and the price level was clear. The Qing Dynasty was the peak period of the development of ancient Chinese painting and calligraphy market. At this time, the marketization degree of painting and calligraphy transaction was high, and the art market mechanism had tended to be perfect. Although the commercialization and marketization of Chinese traditional painting art has a history of thousands of years, the development of Chinese modern art industry is still in the primary stage.

In recent years, under the background of global industrial transfer, The competitiveness and added value of China's art industry are generally weak in the international cultural market, and the significant gap between the creativity of China's art industry and that of foreign developed countries has been highlighted in the international industrial division of labor and cooperation. Therefore, the state attaches great importance to the development of art industry: the report of the 19th National Congress of the Communist Party of China proposed to promote the development of cultural undertakings and cultural industry, and improve the modern cultural industry system and market system; In the outline of the 14th Five-year Plan of the Communist Party of China, the party once again put forward the prosperity and development of cultural undertakings and cultural industries, providing the country with cultural soft power, and emphasized the need to improve the modern cultural industry system. Therefore, it is urgent to extract and absorb the form characteristics, themes, content and spiritual core of traditional Chinese painting art, so as to promote the traditional Chinese painting art to provide inexhaustible creative source for the art industry, and further deepen the connection and integration between traditional Chinese painting art and art industry. And the construction of Chinese traditional painting art industry system, can make Chinese traditional painting art and cultural resources can be fully excavated and utilized, for The Chinese art industry innovation ability to leapfrog the macro scientific guidance. It can be said that the construction and development of Chinese traditional painting art industry system will have outstanding practical significance for the improvement of the added value of China's painting art industry, the further development of China's art industry as a whole, and the significant improvement of its competitiveness in the international market.

\section{Analysis of the Construction Elements of the Industrial System for the Contemporary Inheritance of Chinese Traditional Painting Art}

The inheritance of Traditional Chinese painting art industry is not a simple process in which the functions of a certain element or link are maximized, but a coordinated promotion under a complex system involving the composition of various elements to achieve the integration of inheritance functions. Therefore, to construct the industrial system of contemporary inheritance of Chinese traditional painting art, it is necessary to analyze several essential elements, namely, inheritance subject, inheritance way, inheritance content, inheritance field and inheritance guarantee.

\subsection{Inheritance Subject}

The contemporary inheritance subject of Chinese traditional painting art includes the transmitter and the receiver, the transmitter refers to the transmitter of traditional painting art, the receiver refers to the successor of traditional painting art, and the transmitter and the receiver can transform and influence each other.

In the traditional society, the relationship between the inheritor and receiver of Chinese traditional painting art is simple and pure. In most cases, artists are the main figures in the inheritance of Traditional Chinese painting art, and the purpose of inheritance of traditional painting art is achieved by teaching traditional painting skills to students through the establishment of a mentoring system. In the relation of inheritance between mentoring system mode, so as the artistic 
producers tend to have the right of traditional painting art heritage of "dictatorship", in the hands of the traditional painting art teaching contents, methods of decision and interpretation, even recipients have selected traditional painting art is the disciple of the initiative, in contrast, the disciple is in a relatively passive position, the teacher is almost completely obey, The learned content is basically based on the teacher's teaching and teaching, and is often in the same line with the inheritor in traditional painting skills, forms and styles, which is conducive to the formation of traditional painting art schools. However, this relationship model has certain limitations: The degree to which disciples understand and master the learning content of traditional painting art largely depends on the teacher's level and teaching ability. In addition, a little depends on personal talent, family background or practical experience, etc. Although traditional painting art techniques and styles of famous masters can be well preserved and inherited, But at that time, the judgment of the value of traditional painting art was almost made by the art masters as inheritors, which to some extent limited the recipients' ability to form their own creative and innovative traditional painting art style characteristics. Since the traditional painting art market is relatively mature and has a unique scale, the relationship between the inheritor and the recipient in the subject of inheritance gradually presents a trend of transformation from individual inheritance to group inheritance. With the development of social modernization, the inheritance of traditional Chinese painting art subject scope of all-round expansion, in the traditional painting art tradition industry system, art enterprise as main inheritance of Chinese traditional painting, and so art schools, government agencies, enterprises, folk art groups and the media platform and other tradition common shouldering the important task of the development of Chinese traditional painting art innovation. In this mode of inheritance relationship, the contents, methods, fields and external support of inheritance become complicated due to the wide range of inheritance subjects. Although the space and time distance between the sender and the recipient is relatively long, it may be difficult for the receiver to supervise the receiving and inheritance effect of the recipient of Traditional Chinese painting art. Only by observing the value orientation of the whole society and the changing trend of cultural construction and development can we have an overall grasp of the inheritance result of traditional Chinese painting art. But the interaction between waiters and recipients are strengthened, especially the recipients for the transfer reaction, such as in the traditional painting art market consumer intuitive likes and dislikes tendency to traditional painting art goods would help waiters of traditional painting art work content, form, style, value connotation and marketing strategy, adjust the content of media communication, etc.

With the rapid development of social economy, the traditional Chinese painting art inheritance relationship between the main body pattern more and more complex, the study of its main body individual elements not only passing on isolation, and should master inheritance industry system of each element in the common contact and interaction, on the basis of combination of Chinese traditional painting art inheritance law and industrial development characteristics of modern art, To establish the contemporary inheritance industry development system of Chinese traditional painting art that helps the inheritor to enhance cultural consciousness and the recipient to enhance the artistic spirit realm, and the two assist each other and jointly promote each other.

\subsection{Inheritance Mode}

The method of inheritance is the sum total of the forms, methods, tools, approaches and strategies of cultural inheritance. With the transformation of mode of production and social and economic transformation, traditional painting art industry has become one of the important ways of contemporary inheritance, protection, innovation and development of Traditional Chinese painting art.

In traditional society, traditional painting art commodity trading has been playing an important role in inheriting traditional Chinese painting art. Commodity trading of traditional painting art takes "things" as the medium of inheritance, which is different from other traditional painting art inheritance methods that have strict limits on inheritance subjects. For example, mentoring inheritance is actually the internal communication between creators and producers of traditional painting art. It can expand the scope of the audience for the inheritance of traditional painting art through the market circulation and art consumption link in the art commodity trading, and realize the social benefits of the inheritance of Traditional Chinese painting art and create economic benefits. The traditional painting art market in the Ming and Qing Dynasties has been very prosperous, and has quite perfect trading mechanism and market system. The distinctive economic characteristics and broad market basis of Chinese traditional painting art are enough to provide a strong practical foundation for its industrialization development and the construction of contemporary inheritance industrial system. Therefore, it is an inevitable trend to realize the contemporary inheritance of Chinese traditional painting art through industrial approaches. Traditional Chinese painting art industry inheritance way always with heritage field, so at the time of social productivity development level of Chinese traditional painting art industry play a pivotal role inheritance way, to say the Chinese traditional painting art industry is the modern production technology and production methods under the mature of a dynamic inheritance way. In song dynasty, the traditional painting art commercial trading trend has thrived, in the fierce competition in the art market, driven by masters paintings for ascension yield profit to make a living, the collective created solely by the individual to mill production, however, limited by the time of the productivity development level, although the painting workshop form batch production selling form, still can't produce scale benefit, The strength, effectiveness, scope and time of inheritance are all limited to some extent. Therefore, we need to build the contemporary traditional Chinese painting art heritage industry development system, the traditional Chinese painting art heritage of each link with a combination of the modern advanced science and technology, promote the new era under the way of the Chinese traditional painting art industry innovation, so as to realize the traditional Chinese painting art form of content creation, innovation and value innovation.

\subsection{Inheritance Content}

The inheritance content of Chinese traditional painting art 
mainly refers to the excellent and essence content of Chinese traditional painting art. Chinese traditional painting art is an indispensable part of Chinese excellent traditional culture, so the inheritance of Chinese traditional painting art is to spread the high quality gene of Chinese traditional painting art.

The inheritance of Chinese traditional painting art is rich in content and form and thick in connotation. First of all, it is necessary to have a correct and comprehensive understanding and mastery of Chinese traditional painting art. For example, "brush and ink" is regarded as the core of Chinese painting, but the inheritance content also includes many aspects, including not only the rich and diverse traditional painting art techniques, forms, themes, content and the physical entity of traditional painting art works, etc. It also covers the artistic style, personality, mode of thinking and value orientation of the creators and collectors of traditional painting art revealed and reflected, and even the Chinese nation's aesthetic taste, knowledge structure, folk customs, ethics, religious beliefs and other spiritual contents. Secondly, the content of any traditional culture is due to the time background change to turn better part, so you need to systematically the content of the traditional Chinese painting art heritage carding and differential, eliminating the backward in time, negative, and against the dross part of socialist core values, so as to keep the advanced, positive and connotation of traditional painting art has a very high value. In traditional Chinese painting art heritage content finally, you need to have the possibility of industrialization of scientific evaluation and feasibility for the traditional painting art industrialization is low range of traditional painting art from the art and the modes of production, and other related industrial linkage communication and marketing, etc., targeted to develop its industrial development strategy, So as to promote the inheritance, protection and innovative development of traditional Chinese painting art.

Today's traditional Chinese painting art needs not only to realize its own inheritance and protection, but also to promote the formation and development of the art industry with Chinese characteristics and enhance the soft power of Chinese culture. The inheritance content is the core of the inheritance of Traditional Chinese painting art. Therefore, it is necessary to make use of the industrial development system construction of the contemporary inheritance of Traditional Chinese painting art to clarify the interaction mode between the inheritance content and other elements of the construction of the inheritance system, so as to optimize the contemporary inheritance content of traditional Chinese painting art. Finally, through the traditional painting art industry to achieve the inheritance, protection and innovation of the core of the excellent spirit of Chinese traditional painting art.

\subsection{Inheritance Field}

The inheritance of Traditional Chinese painting art must depend on a certain space. The inheritance field refers to the basic space in which the inheritor transfers the inheritance content of traditional Chinese painting art to the recipient, which can be divided into natural environment space, social and cultural space or a comprehensive space combined with the two. The inheritance field and the inheritance method match each other. Therefore, in the inheritance of traditional painting art industry, the art market is the core field of the inheritance of traditional painting art, and it is an important spatial platform for the communication, communication, movement, inheritance and development of traditional painting art under the combination of natural environment and social and cultural environment.

Art market generally refers to the relatively concentrated space where traditional painting art is circulated and traded among the subjects of inheritance, and the spirit and culture of traditional painting art is spread and exchanged. The art market is distinguished from other traditional painting art inheritance fields by the rich content and fast speed of the dissemination of traditional painting art information. Numerous traditional painting art compete in the market, and the art market becomes a large distribution center of traditional painting art inheritance content. Based on this, the art market for the traditional painting art consumption information feedback mechanism has a great impact on the subject of inheritance. On the negative side, some artists, art enterprises and other inheritance subjects may change their creative intention and motivation to cater to market trend or chase market commercial value after receiving stimulation and influence of market factors. From the positive perspective, some traditional painting art masters, conscientious art enterprises, experts and scholars and other subjects will actively explore the scientific way to combine traditional Chinese painting art and modern art industry, and government agencies will adjust and improve the system and policy of the development of traditional painting art industry accordingly. Therefore, the art market has become an important platform to drive the inheritance and innovation of traditional painting art.

In the early days, the traditional Chinese painting art market often took shape naturally with the commercialization of traditional painting art and the development of traditional painting art industry, and then purposefully through site selection, development and cultivation of artificial traditional painting art market gradually increased. In order to explore the development path of contemporary inheritance industry combining Traditional Chinese painting art and modern art industry, it is necessary to promote those scattered small traditional painting art commodity sales and trading places to gather and form large-scale development. The formation and appearance of fixed traditional painting art trading places in the Song Dynasty is regarded as an important symbol of the development of the art market, which indicates the inevitability of the cluster development of Chinese traditional painting art industry. In the context of cluster development, the content of inheritance field is further expanded. The function of the art market, which originally focused on the commodity trading of traditional painting art, is constantly evolving, forming a new inheritance field that takes into account the experimental research and development base, creation and production base, display and sales market and other functional values. New inheritance between field and other elements of the mechanism of action of interconnected increasingly tend to be more complex, therefore, need to build the contemporary traditional Chinese painting art heritage of industry development system, based on the traditional painting art market law of development, make the traditional painting art industry field of contemporary traditional Chinese painting art heritage industry development fully optimization 
and play an important role in promoting.

\subsection{Inheritance Guarantee}

External support for inheritance mainly refers to inheritance field and inheritance guarantee. The two together constitute the environmental system of the contemporary inheritance industry development system of Chinese traditional painting art. External support for inheritance is not only an important part of the inheritance system, but also a relatively independent external system. The inheritance field and the inheritance guarantee in the external support for inheritance maintain an interactive relationship, while the external support for inheritance interacts with and supports the core link of inheritance.

Guarantee refers to the sum of external forces such as relevant laws, systems, policies, measures and operation mechanisms to ensure the sustainable development of the contemporary inheritance industry of Chinese traditional painting art. In fact, the development of the contemporary inheritance industry of Traditional Chinese painting involves numerous fields, complex contents, wide coverage and arduous tasks. Therefore, it is necessary to rely on the external force of inheritance guarantee to guide, standardize and alleviate various problems in the core link of inheritance. The specific important roles played by inheritance guarantee include: First, heritage protection through development, change the law, system and policy behavior such as the traditional painting art heritage protection and the normal operation of the art industry development, maintenance and urging inheritance subject corresponding exercise their rights and obligations, so as to promote the traditional Chinese painting art based on the industrial development to realize the waiters to spread and continuation of the bearing, Provide important impetus for the industrial development of contemporary inheritance of Chinese traditional painting art; Second, when the contemporary traditional Chinese painting art heritage industry development is blocked, heritage protection can be adjusted according to the existing problems to make corresponding systematic, perfect and innovation, and actively play a role of regulation, and throughout the contemporary traditional Chinese painting art heritage industry development, and heritage industry development information feedback in time, contain the adverse developments, Thus provide important support for the industrial development of contemporary inheritance of Chinese traditional painting art; Thirdly, according to Chinese traditional painting art heritage and art industry development experience of understanding of its laws, to formulate and puts forward the strategic target of proactive, predictive, guide the inheritance and development of the benign interaction, for the traditional Chinese painting art inheritance and industrial development of contemporary core the practice of the art industry chain to provide effective guidance and the external guarantee.

\section{The Construction of Industrial Development System for the Contemporary Inheritance of Chinese Traditional Painting Art}

The industrial system for the contemporary inheritance of
Chinese traditional painting art can be divided into two parts, namely, the external inheritance guarantee system, which is a complex system composed of creative generation, art production, market circulation, art consumption, policy guidance and the linkage of related industries. Only by cooperating with each other and coordinating with each other to form an organic whole, can we realize the construction of the industrial system of contemporary inheritance of Chinese traditional painting art, and promote the continuous optimization and orderly development of traditional painting art inheritance and art industrialization. To sum up, the construction of the industrial system for the contemporary inheritance of Chinese traditional painting art needs to focus on the following aspects:

\subsection{Core Art Industry Chain}

\subsubsection{Idea generation}

The core attribute of the art industry is "creativity". In western developed countries such as Britain and Australia, the art industry is often called "creative industries". It is precisely because the art industry always meets people's spiritual consumption needs by providing creative art commodities or services. Creativity is the foundation and driving force of its existence and development. It can be seen that creative generation is the soul of the art industry, and the core art industry chain is essentially an industrial inheritance path that takes "creativity" as the core and infuses the soul into production, circulation and consumption, so as to realize artistic communication and innovation. Based on this, creative generation is the primary link of the core art industry chain.

Ideas generated in the knowledge economy environment, critical theorist of Frankfurt school, Adorno thought under the standardization production of art would be of the same goods, and the art of the same goods will not be able to get consumer recognition, so as to cater to the market, art producers will try to add new seasoning in his work to achieve remarkable effect. It can be seen that one of the dilemmas of creative generation is that many artists or art enterprises change their styles to cater to the tastes of consumers. Although this compromise has obtained economic benefits, it also leads to the annihilation of the spirit of artistic innovation. Therefore, when the traditional Chinese painting art is constantly impacted by popular culture, art creators, as the decisive factor of creativity generation, should not misread, distort or even erase the distinctive national characteristics in the art noumenon in the transformation and innovation of the traditional Chinese painting art. With the development of Chinese traditional painting art industry, it is necessary to understand and absorb the wind direction and nutrients of mass art, but more importantly, it is necessary to adhere to the principle of the creative spirit of Chinese traditional painting art. The core of creativity is actually Chinese traditional painting art. Traditional Chinese painting as the Chinese nation outstanding traditional culture art treasures, its bright line model and clever pen and ink techniques such as vividly freehand brushwork in traditional Chinese painting's artistic style, and the past of "nature and humanity nature" thought connotation of philosophy, to provide creative art industry generated continuously, inexhaustible creative source, It should be a decisive weapon to form the creative innovation 
of traditional Chinese painting art industry with Chinese characteristics. Therefore, it is necessary to optimize and integrate the resources of Traditional Chinese painting art, based on the original form and connotation of traditional Chinese painting art, find the combination point with the development of The Times, skillfully integrate it, and constantly bring forth the new. In addition, corresponding platforms can be organized to provide high-quality communication and interaction for creative generating subjects, so that they can fully absorb the latest creative ideas and creative experience in various fields, and provide reliable guarantee for creative generation.

\subsubsection{Artistic production}

In the context of the vigorous development of the art industry, contemporary art activities are gradually regarded as a kind of cultural production activities, and the original individual nature of traditional art activities is gradually transformed, which is an inevitable trend faced by contemporary art. However, the development of traditional painting art industry is far behind other art industries, one of the difficulties is that many people are doubtful about whether traditional painting art is suitable to enter the market in batches under the mode of industrial production. Nowadays, in the market economy environment, traditional painting art can not escape being clearly marked, and even economic benefits have gradually become the only way to judge the value of traditional painting art. However, traditional painting art has always been precious because of its originality that cannot be duplicated. Excessive traditional painting art under mechanical reproduction makes it dull. Therefore, as an important part of the industrial development system of the contemporary inheritance of Chinese traditional painting art, it is necessary to explore the scientific and reasonable industrialization production mode of traditional painting art in line with the characteristics of traditional painting art.

Here we first need to distinguish clearly between "industrialization" and "industrialization". The Frankfurt school of critical "culture industry", because in this case, the "industrialization" under mass production via tend to be homogenization, low levels of popular cultural goods, while the "industrialization" claims with creativity as the core, is relying on traditional painting art goods to meet the demand of the public spirit of high quality and high value-added content, Not rely on low cost, no standard of mass production to obtain profits. However, professional painters who are capable of creating unique artistic spirit are doomed to be small in scale and strength. In this case, "industrialization" calls for popularization driven by specialization and systemization formed by aggregation. As a result, the traditional industrialization mode of traditional painting art painting art commodity value is not limited to traditional painting material ontology, but should be creative as the core, according to the different levels of consumer groups for different goods and services for the traditional painting art, and the final form of goods corresponding formulation exclusive production mode of traditional painting art.

W. Benjamin is one of the few scholars in The Frankfurt School who holds an optimistic view of the cultural industry. He believes that the cultural industry transforms the original individual and one-off cultural production and dissemination into the mass reproduction production mode under standardization and modeling. And he argues: "Since then, the 'self-discipline principle' of culture has been replaced by the 'heteronomy principle' of technology, and technological operation has gradually replaced the creation of individuality." However, the author thinks that in the industrialization of traditional painting art, technical operation does not replace individual creation, but the main body of creative generation and art generation (producer of art commodity material entity) is gradually separated. With the improvement of the market and production technology mature, people use modern means of science and technology resources, the development and utilization of the traditional Chinese painting art generated accord with era characteristics and connotation of traditional Chinese painting art creation, to inject new vitality for the traditional painting art industry, linkage related emerging industries, and actively create the emerging forms of traditional painting art tradition industry, Finally, the art industry becomes the carrier of contemporary inheritance of Chinese traditional painting art, which is the meaning and application of art production under the development system of contemporary inheritance industry of Chinese traditional painting art.

\subsubsection{Market circulation}

The industrialization of traditional painting art is inseparable from the role of the market, and the consumption and inheritance of traditional painting art need to be realized through the key link of market circulation. Traditional painting art commodity market circulation is a relatively complex process, it seems to have been out of the scope of art, more on economic level, the traditional painting art market is, however, traditional painting art based on the circulation of commodities trading places, therefore, should follow the rules of the general market, also want to fit the unique characteristics of traditional painting art.

Market economy is the main form of economic activities in modern society. The art market under the traditional painting art industry also plays a role in allocating traditional painting art resources. In the traditional painting art market, the seller provide the traditional painting art of goods and services to realize the transmission of traditional painting art, and the buyer by paying money to finish art consumption, the behavior of the buyers and sellers, to some extent, feedback the market information, according to the existing market information can be estimated in a certain extent on the future of traditional painting art market. At this point, the seller needs to have a keen sense of these market information, so as to grasp the development rules of the traditional painting art market, so as to formulate the marketing strategy of the traditional painting art market. Marketing strategy for the traditional painting art commodity sales planning investment, communication and promotion, commodity distribution, storage and transportation are indispensable, it is not only the traditional painting art into the market economy environment necessary process, but also improve the traditional painting art market economic benefits of the program set. Marketers in the market circulation, art will be according to the different market environment, traditional painting art fully excavate the consumption psychology of the audience market and spread 
through various channels to increase the traditional painting art commodity market propaganda, for consumers in the traditional painting art and marketers to fully trust, thus effectively stimulate consumer purchasing desire. Scientific and reasonable marketing strategies help traditional painting art commodities to enhance their market influence, and with the help of modern media platforms, can effectively promote the construction of traditional painting art quality brand. In addition, in addition to buyers and sellers, the art market of traditional painting art industry is also affected by another special subject, namely art critics. It can be said that art marketers stimulate and enhance the economic added value of traditional painting art based on the perspective of economy and market, while art critics explore and judge the art core spirit of traditional painting art commodities from the perspective of traditional painting art aesthetics. Art critics can be professional traditional painting masters, aestheticians, art theorists and art educators. They can also be free people who have not received professional training but are influential enough to represent public reputation and response due to personal interests. With the development of online information platforms, art critics have an increasing influence on the circulation and marketing of traditional painting art market.

With the gradual deepening of commercialization, the comprehensive value of traditional painting art commodities seems to be all economic value. At this time, some art marketers eager for quick success and quick profits attempt to wanton dominate the trend of traditional painting art through rhetoric and exaggerated publicity. However, the comprehensive value of traditional painting art is always determined by the core spiritual value, and the superficial vulgar traditional painting art will eventually be questioned by the public. As a result, these traditional paintings in the art market marketers should adhere to the principle of traditional painting art aesthetic value is preferred, good spirit of Chinese traditional painting art, earnestly formulate reasonable as far as possible to the mutual benefit of both artists and consumers marketing strategy, in order to build a good sound traditional painting art market environment, Jointly promote the benign circulation of traditional painting art market development.

\subsubsection{Art consumption}

Art consumption is a unique aesthetic activity that satisfies the spiritual needs of art through the purchase of artistic commodities or artistic services. With the development of economy and the progress of science and technology, the ways and methods of art consumption become more and more convenient and diversified. The audience market of traditional painting art is expanding and the subjects of art consumption are increasing, which promotes the development of traditional painting art industry to a certain extent.

In the process of traditional painting art consumption, art consumers through the purchase of art goods, enjoy art services and art appreciation activities, their own psychological state, aesthetic ability and spiritual realm has been eased and improved, and this improvement may produce positive and effective qualitative changes in the accumulation of time and months. In this way, the aesthetic level is promoted in the creative generation of traditional painting art and the goal and direction of the reproduction of traditional painting art are guided. However, the positive interaction between the commodities of traditional painting art and the consumers needs to be guaranteed by the industrial development system of contemporary inheritance of Traditional Chinese painting art. As art consumption always depends on the aesthetic level and value choice of the consumer, some painting art commodities may gradually become popular and vulgar in order to blindly cater to the needs of the market mass. On the contrary, some painting art commodities may be more extreme in artistic style, resulting in a state too profound and ultimately no one can understand and appreciate. Therefore, it is necessary to guide creative generation, art production and market circulation through the industrial development system of contemporary inheritance of Traditional Chinese painting art to fully absorb the profound value and connotation contained in the resources of traditional Chinese painting art and integrate them into traditional painting art commodities, so as to lay a foundation for art consumption. In addition, it is necessary to realize the cognition and education function of traditional painting art by means of art consumption. Throughout ancient and modern times, numerous excellent traditional painting art works have a subtle promotion effect on the formation and shaping of ideal personality.

The vigorous development of the industrialization of traditional Chinese painting art, reduces the appreciate and enjoy the threshold of the traditional painting art, make the public can participate in art activities, by means of art consumption makes artists get considerable economic benefit at the same time, while art consumption is a traditional Chinese painting art tradition industry plays an important role in promoting the continuous development. In the industrial development system of Chinese traditional painting art inheritance, it is not only the ultimate realization of Chinese traditional painting art inheritance, but also the primary link of a new round of Chinese traditional painting art inheritance and development.

\subsection{External Inheritance Guarantee System}

\subsubsection{Regulation of policies and regulations}

Art industry policies and regulations are the sum of policies and regulations formulated and implemented by the state and government to guide and regulate the development of art industry. Different from other general industrial policies and regulations, the key point of art industry policies and regulations is that when attaching importance to the economic development and market benefits in the development of art industry, ideology and social benefits of art industry should be taken into account. Market-oriented, painting art industry development in our country, but not always rely on the market value law and the supply and demand adjustment, many art market adverse phenomenon to policies and regulations need to be guided and restriction, therefore, the contemporary traditional Chinese painting art heritage of industry development and system construction needs to be further perfect art industry policies and regulations, Effective protection of traditional Chinese painting art, which represents the fine tradition and glorious history of the nation, provides practical guidance and external guarantee for the 
development direction of the art industry.

Many countries with profound historical and cultural heritage of painting art have obvious policy preference for their national painting art and classical painting art. These precious traditional painting art can be protected and continued by the active maintenance of governments of various countries, which in turn can improve the aesthetic height and artistic cultivation of the whole nation. As a unique painting art form in China, traditional Chinese painting art needs the state and government to vigorously create a good industrial development environment and open up a path for the contemporary inheritance of traditional Chinese painting art. The development policies and regulations of China's art industry must fully consider the uniqueness of Chinese traditional painting art. For the part of Chinese traditional painting art that is not suitable for industrial development, the state and the government can jointly mobilize social forces to provide appropriate funding and support; For those suitable for the market, it will advocate and encourage them to carry out the inheritance and innovation of painting art creation from the perspective of policies, so as to help improve their competitiveness in the art market. In addition, what the government needs to do more is to examine and approve, supervise and standardize production, circulation and consumption in the development of the contemporary inheritance industry of Chinese traditional painting art, establish a market system, and create an orderly, honest and high-quality art market. However, the traditional painting art industry development of our country has just started, a vast amount of chaos in the art market, shall be promulgated by the state organs culture as needed economic relevant regulatory documents or art industry special laws, such as enterprises, marketing, such as copyright law, and makes positive standard controls and reverse restrictions on work together, In order to provide effective external guarantee and support for the core art industry chain in the industrial development system of contemporary inheritance of Chinese traditional painting art.

\subsubsection{Linkage of related industries}

With the change of current economic structure and consumer demand, industries are more and more closely related to each other, and integrated development has become an inevitable trend of industrial development. Art industry and the related industrial linkage can produce promoting integration development of superposition and benefit, especially the industry of traditional Chinese painting art tradition, audience can extend the painting art consumption market and enhance their own brand benefit and influence, and make their own benefit at the same time reaction in related industries, achieve mutual benefit together. Therefore, linkage with related industries has become an important way and strong support for the development and system construction of the contemporary inheritance industry of Chinese traditional painting art.

The cohesion of Chinese traditional painting art the core industrial chain and extension ability is stronger, the core industrial chain to artists, artisans, vendors and advertisers, dealers involved in many subjects, and drive a lot for the painting art industry to provide complementary products related supporting industries such as painting art education training, painting materials production and sales, etc. And associated art design enterprises and institutions such as art colleges and universities, art design companies, and indirectly linked tourism, etc. Based on this, the contemporary traditional Chinese painting art heritage of industry development not only has a certain advantage in absorbing labor force employment, can directly increase the talent employment related industries, also can pass and the related industrial linkage to inject new vitality, enrich the cultural connotation and spirit value of related industry, enhance the competitive advantage of relative industries, And drive the economic development of the surrounding cities.

With the progress of science and technology and the spirit of consumer demand change, in the traditional Chinese painting art commodity individuation, hierarchical and industrialization driven by need to grasp the traditional Chinese painting art tradition industry and related industrial linkage of an important opportunity, thus promoting the economic development, personnel training, technology innovation, construction of disciplines related industrial linkage efficiency gains, It has promoted the revitalization of Chinese traditional painting art industry, provided power for the development system of contemporary inheritance industry of Chinese traditional painting art, and finally promoted the realization of comprehensive benefits such as economic, cultural and social development of contemporary inheritance of Chinese traditional painting art.

\section{Acknowledgement}

General project of Humanities and Social Sciences of Education Department of Jiangxi Province: Research on industrial Development System of Contemporary Inheritance of Chinese Painting Art (No.:YS20101); General project of Jiangxi Provincial Social Science Planning: Research on landscape Activation Design of Industrial Heritage from the perspective of Landscape Narrative (No.:21YS06); General Project of Social Science Planning of Jiangxi Province: Narrative Design of urban Red Landscape (No. 20YS06); General project of cultural and art planning science in Jiangxi Province: Research on the construction method of urban red landscape from the perspective of narratology (No.:YG2020033).

\section{References}

[1] A. Bonnaccorsi, "On the Relationship between Firm Size and Export Intensity," Journal of International Business Studies, XXIII (4), pp. 605-635, 1992. (journal style)

[2] Duan Chao. Research on the construction of contemporary inheritance system of Chinese excellent traditional culture $[\mathrm{J}]$. Journal of South-central University for Nationalities (Humanities and Social Sciences Edition), 2012, 32(02): 1-6.

[3] Zhang Zhongbo. On systematic elements of industrialization of folk art[J]. Journal of Henan University (Social Science Edition), 2015, 55(02): 125-132.

[4] Bai Guixi. Inheritance system and construction of national traditional culture-Based on system theory 
and cybernetics[J]. Journal of Southwest University for Nationalities: Humanities and Social Science Edition, 2017 (05): 62-67.

[5] Li Xianming, Cheng Jichun. The construction of Chinese excellent traditional culture inheritance system: Theory, practice and path[J]. Nanjing Social Sciences, 2016 (11) :138-145.

[6] WANG Zhengguo. On the construction of excellent traditional culture inheritance system[J]. Journal of Guizhou Normal University (Social Science Edition), 2012(02):49-55.

[7] $\mathrm{Gu}$ Zhaogui. Introduction to art economics[M].Beijing: Culture and Art Publishing House, 2004.

[8] Peng Xiuyin. On traditional Chinese painting art[M]. Taiyuan: Shanxi Education Press, 2001.

\section{Author Profile}

Hui Lin (1966.9-), male, Yushan, Jiangxi, China. Professor of College of Urban Construction, Jiangxi Normal University, research direction: interior decoration and landscape design.

Yan Cheng (1997.9-), female, Ganzhou, Jiangxi, China. Master of Environmental Art, College of Fine Arts, Jiangxi Normal University.

Xiaogang Chen (1978.9-), male, Duchang, Jiangxi Province, Associate professor, master's supervisor, teacher of School of Urban Construction, Jiangxi Normal University, research direction: landscape architecture planning theory and design. 